\title{
Взаимодиффузия и фазообразование в тонкопленочной системе $\mathrm{Fe}-\mathrm{TiO}_{2}$
}

\author{
(C) Н.Н. Афонин ${ }^{1}$, В.А. Логачева ${ }^{2}$ \\ ${ }^{1}$ Воронежский государственный педагогический университет, \\ 394043 Воронеж, Россия \\ ${ }^{2}$ Воронежский государственный университет, \\ 394018 Воронеж, Россия \\ E-mail: nafonin@vspu.ac.ru
}

(Получена 30 января 2017 г. Принята к печати 8 февраля 2017 г.)

Методами рентгенофазового анализа, вторично-ионной масс-спектрометрии, атомно-силовой микроскопии и математического моделирования исследовано взаимодействие магнетронным способом распыленного металлического железа с пленками оксида титана в процессе изотермического вакуумного отжига. Предложен механизм формирования сложных оксидов на границах зерен, основанный на реакционной диффузии металла Fе в оксид титана. Разработана количественная модель реакционной взаимодиффузии в двухслойных поликристаллических пленочных системах металл-оксид с ограниченной растворимостью компонентов. Численным анализом экспериментальных концентрационных распределений металлов в пленочной системе $\mathrm{Fe}-\mathrm{TiO}_{2}$ определены значения индивидуальных коэффициентов диффузии: железа $8.0 \cdot 10^{-13} \mathrm{~cm}^{2} / \mathrm{c}$ и титана $3.0 \cdot 10^{-15} \mathrm{~cm}^{2} / \mathrm{c}$ в условиях вакуумного отжига при $1073 \mathrm{~K}$.

DOI: $10.21883 /$ FTP.2017.10.45012.8531

\section{1. Введение}

Диоксид титана со структурой рутила является широкозонным $(\sim 3.2$ эВ) оптически прозрачным полупроводником $n$-типа и находит широкое применение в составе защитных, самоочищающихся покрытий [1] как фотокатализатор для бытовой и промышленной очистки воды и воздуха [2], компонент сенсорных датчиков [3]. Функциональные свойства диоксида титана можно контролировать путем модифицирования его различными добавками. В ряде работ для этой цели диоксид титана легировали ионами щелочно-земельных металлов: $\left(\mathrm{Ca}^{2+}\right.$, $\mathrm{Sr}^{2+}$ и $\mathrm{Ba}^{2+}$ ) [4]; переходных металлов: $\mathrm{Fe}^{3+}[5], \mathrm{Co}^{2+}[6]$, $\mathrm{Cr}^{3+}, \mathrm{Ni}^{2+}, \mathrm{Cu}^{2+}, \mathrm{Nb}^{5+}$ [7], а также редкоземельных элементов: $\mathrm{La}^{3+}, \mathrm{Ce}^{3+}, \mathrm{Sm}^{3+}[8,9]$. Катионы металлов могут либо замещать титан, либо внедряться в междоузлия, но механизм легирования диоксида титана не всегда ясен. При этом важными факторами являются природа, концентрация легирующей примеси и температура отжига.

Легирование железом частиц $\mathrm{TiO}_{2}$ приводит к образованию смешанных оксидов или смеси простых и смешанных оксидов [10]. Катионы железа $\mathrm{Fe}^{3+}$ замещают $\mathrm{Ti}^{4+}$ в катионных позициях, так как имеют близкие ионные радиусы $\mathrm{Fe}^{3+}(0.64 \AA), \mathrm{Ti}^{4+}(0.610 \AA)$ и образуют твердые растворы с диоксидом титана при низких концентрациях железа $(<1 \%)$. В зависимости от применяемой термической обработки и содержания железа в системе $\mathrm{Fe}-\mathrm{Ti}$ могут образовываться различные смешанные оксиды: $\mathrm{FeTiO}_{3}$ (ильменит), $\mathrm{Fe}_{2} \mathrm{TiO}_{4}$ (ульвошпинель), $\mathrm{Fe}_{2} \mathrm{TiO}_{5}$ (псевдобрукит), $\mathrm{Fe}_{2} \mathrm{Ti}_{3} \mathrm{O}_{9}$ (псевдорутил) [11].

Модифицирование оксида титана железом осуществлялось различными способами: гидротермальным методом [5], золь-гель методом [12,13], плазменной обработкой [14], магнетронным распылением [15], методом ионной имплантации [16].
С развитием ионно-плазменных методов обработки материалов с целью модифицирования их свойств возникает необходимость в исследованиях процессов диффузии и фазовых превращений в модифицированных слоях. Одним из методов исследования таких систем является компьютерное моделирование [17], основанное на законах Фика и сохранения массы в предположении механизма диффузии по непрерывным каналам. В рамках модели проведен анализ термически индуцированных процессов диффузии и фазообразования в полученной имплантацией системе металл-металлоид $\mathrm{Fe}: \mathrm{O}^{+}$. Характер фазовых превращений в исследованной системе определяется изменением локальной концентрации компонентов в процессе межузельной диффузии кислорода и отражает особенности фазовой диаграммы равновесных состояний бинарной системы $\mathrm{Fe}-\mathrm{O}$.

Актуальным является исследование механизма модифицирования оксида титана различными примесями для управления его функциональными свойствами.

Цель настоящей работы заключается в комплексном исследовании процессов диффузии и фазообразования при взаимодействии железа с тонкими пленками оксида титана.

\section{2. Методика эксперимента}

Методом магнетронного распыления на пластины монокристаллического кремния осаждали пленку металлического титана толщиной 100 нм. Для получения оксида титана осуществляли термообработку в печи резистивного нагрева в потоке кислорода при $T=973 \mathrm{~K}$ в течение 30 мин.

Пленки оксида титана модифицировали магнетронным распылением железа в модернизированной установке 

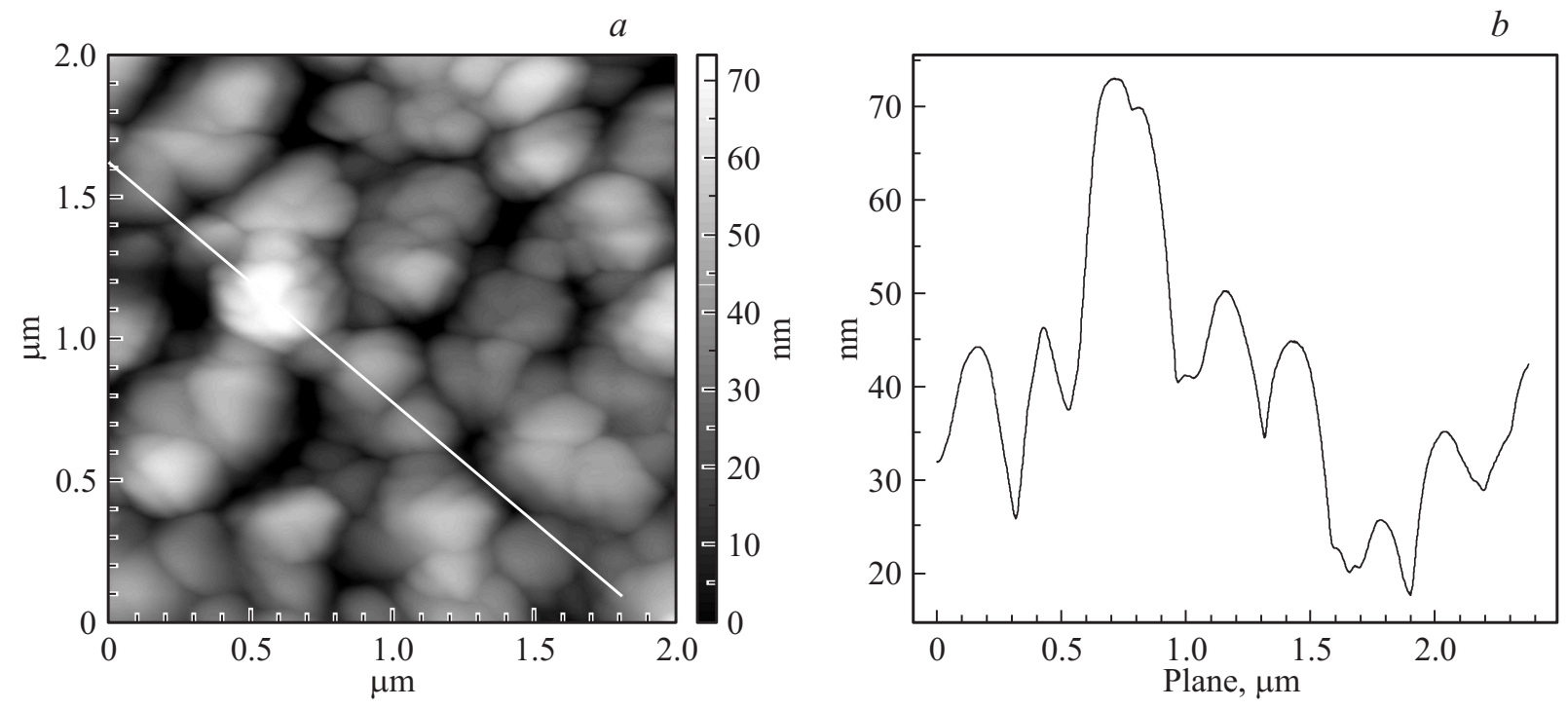

Рис. 1. АСМ-изображение поверхности $2 \times 2$ мкм пленочной системы $\mathrm{Fe}-\mathrm{TiO}_{2} / \mathrm{Si}$ после отжига в вакууме при $T=1073 \mathrm{~K}$ : $a$ - топография поверхности; $b-$ сечение рельефа поверхности структуры.

УВН-1 в плазме аргона при режимах: давление в камере $13.3 \cdot 10^{-2}$ Па, ток разряда $0.5 \mathrm{~A}$, напряжение разряда $420 \mathrm{~B}$, с последующим отжигом в вакууме в диапазоне температур $673-1073 \mathrm{~K}$ в течение 30 мин. Материалом катода служила мишень металлического железа с содержанием примесей не более 0.01 ат\%. Скорость распыления железа составила 7.2 нм/мин, толщина пленки задавалась временем распыления и составляла от 90 до 120 нм.

Дифрактометрическое исследование in situ фазовых превращений в пленочной системе $\mathrm{Fe}-\mathrm{TiO}_{2} / \mathrm{Si}$ в процессе изотермического отжига в температурном интервале от 303 до $1073 \mathrm{~K}$ проводили в вакуумной камере дифрактометра ARL X'TRA при давлении $P=1.33 \cdot 10^{-2}$ Па с использованием $\mathrm{Cu} K_{\alpha_{1}}$-излучения $(\lambda=1.540562 \AA)$ в интервале углов $20-80^{\circ}$ с шагом $0.06^{\circ}$. Идентификация фазового состава пленочных образцов проведена путем сопоставления набора межплоскостных расстояний и интенсивностей с Международной базой данных JCPDS-ICDD [18]. Распределения компонентов по глубине пленочной системы определяли методом вторичной ионной масс-спектрометрии (ВИМС) на установке Cameca IMS7f с использованием пучка первичных ионов $\mathrm{Cs}^{+}$c энергией 3 кэВ.

Исследование морфологии поверхности пленок проводили методом атомно-силовой микроскопии (ACM) на сканирующем зондовом микроскопе Solver P47PRO в полуконтактном режиме с использованием кантилевера NSG11S.

\section{3. Результаты эксперимента и их обсуждение}

Дифрактометрическое исследование in situ фазовых превращений в процессе изотермического отжига в вакуумной камере показало, что при модификации тонкопленочного оксида титана в структуре рутила железом после магнетронного распыления происходит взаимодействие металлического железа с оксидом титана с образованием оксида железа $\mathrm{Fe}_{3} \mathrm{O}_{4}$ (магнетита). Отжиг до $T=873 \mathrm{~K}$ не меняет фазового состава пленки. При $T=973 \mathrm{~K}$ образуются фазы сложных оксидов: $\mathrm{FeTiO}_{3}$ (ильменит) ромбоэдрической структуры и $\mathrm{Fe}_{2} \mathrm{TiO}_{4}$ (ульвошпинель) кубической модификации, которая кристаллизуется в структуре обращенной шпинели и образует непрерывные твердые растворы с магнетитом. При этой же температуре наряду с оксидными фазами титана и железа появляются дифракционные пики металлического титана. После отжига при $T=1073 \mathrm{~K}$ растет интенсивность рефлексов, принадлежащих фазам сложных оксидов $\mathrm{FeTiO}_{3}$ и $\mathrm{Fe}_{2} \mathrm{TiO}_{4}$ и образуется оксид железа $\mathrm{Fe}_{2} \mathrm{O}_{3}$ ромбоэдрической модификации.

Анализ морфологии поверхности на основе АСМ-изображений показал, что пленка $\mathrm{Fe}-\mathrm{TiO}_{2} / \mathrm{Si}$ после магнетронного распыления была поликристаллической, c характерным размером зерен 14-20 нм. После вакуумного отжига при $T=1073 \mathrm{~K}$ размер зерен увеличился до 30-50 нм; каждое отдельное зерно состоит из нескольких более мелких, имеющих овальную форму (рис. 1).

На рис. 2 представлены концентрационные распределения железа (символы 1) и титана (символы 2) по глубине пленочной системы $\mathrm{Fe}-\mathrm{TiO}_{2}$ после магнетронного осаждения железа на оксид титана. Пленка состоит из двух слоев: внешнего металлического слоя железа толщиной 120 нм и оксида титана толщиной 250 нм. Характер концентрационных распределений свидетельствует о том, что перемешивание компонентов происходит уже в процессе магнетронного распыления, причем размер переменной по концентрации области $(\sim 25 \mathrm{HM})$ соизмерим с толщиной нанесенной пленки железа. 


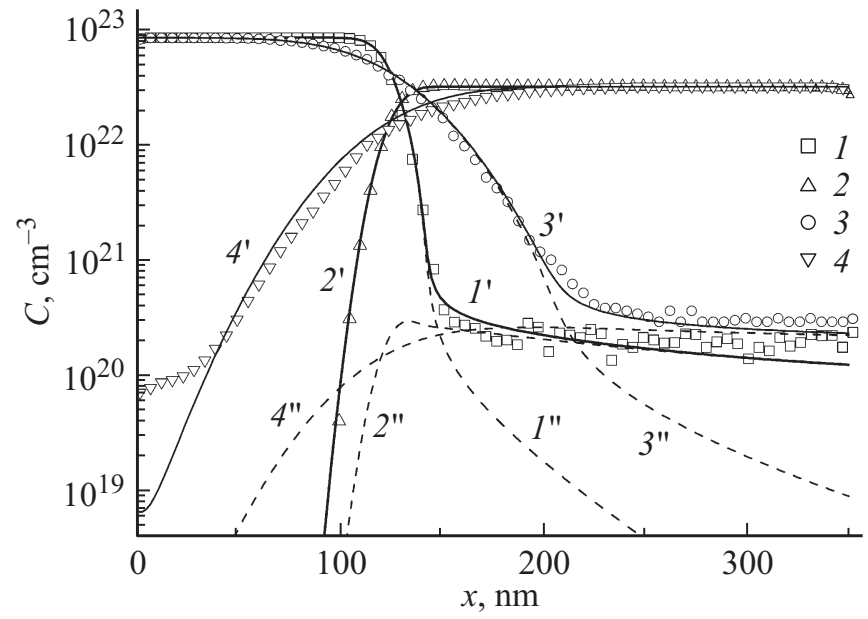

Рис. 2. Экспериментальные (ВИМС) (1-4) и расчетные $\left(1^{\prime}-4^{\prime}, 1^{\prime \prime}-4^{\prime \prime}\right)$ распределения по глубине пленочной системы $\mathrm{Fe}-\mathrm{TiO}_{2}$ полной $\left(1^{\prime}-4^{\prime}\right)$ и свободной части $\left(1^{\prime \prime}-4^{\prime \prime}\right)$ концентрации $C$ металлов. Символы: $1,3-\mathrm{Fe}, 2,4-\mathrm{Ti}$; кривые: $1^{\prime}, 1^{\prime \prime}-\mathrm{Fe}, 2^{\prime}, 2^{\prime \prime}$ - Ті после магнетронного распыления железа на оксид титана и $3^{\prime}, 3^{\prime \prime}-\mathrm{Fe}, 4^{\prime}, 4^{\prime \prime}-\mathrm{Ti}$ после вакуумного отжига в режиме $T=1073, t=30$ мин.

В ходе последующего вакуумного отжига системы $\mathrm{Fe}-\mathrm{TiO}_{2}$, начиная с температуры $973 \mathrm{~K}$, методом РФА установлено образование фаз сложных оксидов. С увеличением температуры отжига до 1073 К протяженность переменной по концентрации области на межфазной границе $\mathrm{Fe}-\mathrm{TiO}_{2}$ возрастает до $\sim 70$ нм. Увеличивается концентрация железа в пленке оксида титана с образованием участка однородного легирования (рис. 2, символы 3) и титана в пленке железа (символы 4).

Наблюдаемые результаты экспериментальных исследований можно объяснить в предположении реакционной диффузии железа в оксид титана с распределенным по глубине $\mathrm{TiO}_{2}$ образованием фаз сложных оксидов.

\section{4. Модель и результаты численного анализа}

Железо в монокристаллическом оксиде титана в структуре рутила имеет растворимость, не превышающую $0.1-0.2$ aт\% [19]. Однако в пленке $\mathrm{TiO}_{2}$, имеющей поликристаллическую структуру, можно ожидать более высокой растворимости вследствие накопления железа в межзеренном пространстве и его способности замещать титан в катионных позициях оксида. Будем полагать, что проникновение железа внутрь кристаллитов оксида титана отсутствует.

Диффундируя по границам зерен, железо испытывает сегрегационный захват на них. Центрами захвата выступают координационно-ненасыщенные атомы титана, выходящие на поверхность зерен. Атомы Fe, мигрирующие в пленке $\mathrm{TiO}_{2}$, иммобилизуются на границах зерен $\mathrm{TiO}_{2}$ как на ловушках, теряя свою подвижность. Эта стадия процесса, вероятно, носит характер физической сорбции, без химического взаимодействия.

На следующей стадии процесса происходит замещение железом титана в оксиде с высвобождением свободного, способного к миграции титана. Захваченные на ловушки атомы железа способствуют ослаблению и разрыву соседних ковалентных связей полупроводника, в нашем случае $\mathrm{TiO}_{2}$, и замене их на связи $\mathrm{Fe}-\mathrm{O}$ с восстановлением титана в элементарной форме:

$$
\mathrm{A}+\mathrm{B} \stackrel{k_{1}}{\longrightarrow} \mathrm{D}+\mathrm{C}
$$

где А - свободное железо, В - титан в составе ловушек на межзеренных границах его оксида, C свободный титан, D - железо в составе его оксида, заменившее титан в структуре его зернограничных ловушек, $k_{1}$ - константа скорости реакции.

Захват железа на ловушки будет происходить до тех пор, пока все они не заполнятся и, следовательно, не будет переведен в свободную форму весь имеющийся в них титан. Вследствие низкой растворимости железа в оксиде титана даже при высоких температурах на развитой стадии процесса $\mathrm{Fe}$ не может заместить весь находящийся в пленке оксида, связанный с кислородом Ті. Вступившее в химическую связь с кислородом железо дает основу для дальнейшего образования обнаруженных РФА в условиях эксперимента оксидов железа $\left(\mathrm{Fe}_{3} \mathrm{O}_{4}\right.$ и $\left.\mathrm{Fe}_{2} \mathrm{O}_{3}\right)$. Замещенные железом атомы титана частично диффундируют в пленку железа, а оставшиеся в пленке $\mathrm{TiO}_{2}$ образуют сложные оксиды железа и титана $\left(\mathrm{FeTiO}_{3}\right.$ и $\left.\mathrm{Fe}_{2} \mathrm{TiO}_{4}\right)$.

Как следствие, на поверхности зерен оксида титана образуется оболочка из сложных оксидов железа и титана. В результате исходная пленка $\mathrm{TiO}_{2}$ становится гетерофазной. Образовавшиеся сложные оксиды распределены внутри довольно протяженной реакционной зоны, соизмеримой с исходной пленкой $\mathrm{TiO}_{2}$. Это свидетельствует о том, что процесс фазообразования контролируется не твердофазной реакцией, а диффузией подвижных компонентов - свободного железа и титана. Образование оксидов происходит в этом случае не путем послойного роста на границе раздела фаз, а по всей толщине пленки по границам зерен $\mathrm{TiO}_{2}$.

Подвижными компонентами в реакции (1) являются атомы свободного $\mathrm{Fe}$ и Ti, образовавшегося в результате замещения его железом на поверхности зерен оксида титана. Если начало системы отсчета положить на внешней границе пленки железа, то при соотношении индивидуальных коэффициентов диффузии металлов $\left(D_{\mathrm{A}} \gg D_{\mathrm{C}}\right)$ на развитой стадии процесса имеем перемещение межфазной границы $\mathrm{Fe}-\mathrm{TiO}_{2}$ к поверхности пленочной системы вследствие эффекта Киркендалла [20]. При этом структурные фрагменты оксида титана, находящиеся внутри зерен и не вступающие в химическое взаимодействие с железом, будут эффективно перемещаться к внешней границе системы, играя роль инертных меток в опыте Смигельскаса и Киркендалла [20]. 
Согласно теории Даркена [21], в бинарной системе с неограниченной растворимостью взаимная диффузия описывается краевой задачей для двух уравнений, содержащих один эффективный коэффициент взаимодиффузии, являющийся линейной комбинацией индивидуальных коэффициентов диффузии компонентов. Одно из основных положений теории [21] связано с отсутствием учета возможных химических превращений в процессе взаимодиффузии и предположением о неизменности мольного объема системы, связанного с изменением его состава.

Теория, представленная в работе [21], применяется к образованию и росту пограничных фаз в диффузионной зоне [22,23]. В работе[24] она впервые развита на случай объемных реакций образования силицидов металла в процессе взаимодействия пленки силицидообразующего металла $\mathrm{Ni}$ c SiC. Модель работы [24] не позволяет хорошо описать перераспределение компонентов внутри имеющей большую протяженность реакционной зоны, что связано, на наш взгляд, с отсутствием учета изменения мольного объема системы в процессе силицидообразования. Вопрос о распространении теории, представленной в работе [21], на реакционный случай остается открытым.

В нашем случае неизменность мольного объема системы обусловлена образованием твердых растворов замещения на основе оксида титана, а также тем, что в твердофазной реакции участвуют только атомы титана, расположенные на границах зерен, составляющие незначительную долю от связанного с кислородом титана в $\mathrm{TiO}_{2}$. Поэтому полагаем, что в системе $\mathrm{Fe}-\mathrm{TiO}_{2}$ диффузионное перемешивание $\mathrm{Fe}, \mathrm{Ti}$ (в составе $\mathrm{TiO}_{2}$ ) и восстановленного Ті также может быть описано с помощью эффективного коэффициента взаимодиффузии.

Уравнения задачи, описывающей взаимодиффузию в пленочной системе $\mathrm{Fe}-\mathrm{TiO}_{2}$, учитывают реакцию на границах зерен с помощью введения кинетических (реакционных) членов и имеют вид:

$$
\begin{aligned}
\frac{\partial C_{\mathrm{A}}}{\partial t}=\frac{\partial}{\partial x}\left(D^{*} \frac{\partial C_{\mathrm{A}}}{\partial x}\right)-k_{1}\left(C_{\mathrm{B}} \cdot C_{\mathrm{A}}\right), \\
\frac{\partial C_{\mathrm{B}}}{\partial t}=\frac{\partial}{\partial x}\left(D^{*} \frac{\partial C_{\mathrm{B}}}{\partial x}\right)-k_{1}\left(C_{\mathrm{B}} \cdot C_{\mathrm{A}}\right), \\
\frac{\partial C_{\mathrm{C}}}{\partial t}=\frac{\partial}{\partial x}\left(D^{*} \frac{\partial C_{\mathrm{C}}}{\partial x}\right)-k_{1}\left(C_{\mathrm{B}} \cdot C_{\mathrm{A}}\right), \\
\frac{\partial C_{\mathrm{D}}}{\partial t}=\frac{\partial}{\partial x}\left(D^{*} \frac{\partial C_{\mathrm{D}}}{\partial x}\right)-k_{1}\left(C_{\mathrm{B}} \cdot C_{\mathrm{A}}\right), \\
\frac{\partial C_{\mathrm{F}}}{\partial t}=\frac{\partial}{\partial x}\left(D^{*} \frac{\partial C_{\mathrm{F}}}{\partial x}\right),
\end{aligned}
$$

где $t$ - время, $x$ - глубина, отсчитываемая от внешней поверхности пленки металла, $C_{\mathrm{A}}, C_{\mathrm{B}}, C_{\mathrm{C}}, C_{\mathrm{D}}, C_{\mathrm{F}}-$ концентрации компонентов: $C_{\mathrm{A}}-$ свободного железа, $C_{\mathrm{B}}$ - титана, входящего в состав ловушек на межзеренных границах оксида $\mathrm{TiO}_{2}, C_{\mathrm{C}}-$ свободного титана,
$C_{\mathrm{D}}-$ связанного железа в составе его оксида и $C_{\mathrm{F}}-$ титана, входящего в состав стехиометрического оксида внутри зерен, не участвующего в реакции.

Эффективный коэффициент взаимодиффузии $D^{*}$ в нашем случае имеет вид

$$
D^{*}=\frac{D_{\mathrm{A}}\left(C_{\mathrm{B}}+C_{\mathrm{C}}\right)+D_{\mathrm{C}}\left(C_{\mathrm{A}}+C_{\mathrm{D}}\right)}{C_{t}},
$$

где $D_{\mathrm{A}}$ и $D_{\mathrm{C}}$ - индивидуальные коэффициенты диффузии свободных подвижных компонентов железа и титана соответственно, $C_{t}=C_{\mathrm{A}}+C_{\mathrm{B}}+C_{\mathrm{C}}+C_{\mathrm{D}}$ - общая концентрация активных компонентов системы.

На границах пленочной системы $\mathrm{Fe}-\mathrm{TiO}_{2}$ полагалось условие отражения:

$$
\begin{gathered}
\frac{\partial C_{\mathrm{A}}}{\partial x}=\frac{\partial C_{\mathrm{B}}}{\partial x}=\frac{\partial C_{\mathrm{C}}}{\partial x}=\frac{\partial C_{\mathrm{D}}}{\partial x}=\frac{\partial C_{\mathrm{F}}}{\partial x}=0 \\
\text { при } \quad x=0 \quad \text { и } \quad x=L .
\end{gathered}
$$

Начальными условиями для уравнений (2)-(6) при моделировании перераспределения компонентов в процессе магнетронного распыления являются:

$$
\begin{gathered}
C_{\mathrm{A}}(x, 0)=N_{\mathrm{SA}}, \quad C_{\mathrm{B}}(x, 0)=C_{\mathrm{F}}(x, 0)=0 \text { при } 0 \leq x \leq h, \\
C_{\mathrm{A}}(x, 0)=0, \quad C_{\mathrm{B}}(x, 0)=r \cdot N_{\mathrm{SF}}, \\
C_{\mathrm{F}}(x, 0)=(1-r) \cdot N_{\mathrm{SF}}, \quad \text { при } h<x \leq L, \\
C_{\mathrm{D}}(x, 0)=C_{\mathrm{C}}(x, 0)=0 \quad \text { при всех } \quad 0 \leq x \leq L, \quad(10)
\end{gathered}
$$

где $h$ - толщина пленки железа, $L-$ толщина пленки $\mathrm{TiO}_{2}, N_{\mathrm{SA}}-$ собственная концентрация атомов металла $\left(N_{\mathrm{SA}}=8.48 \cdot 10^{22} \mathrm{~cm}^{-3}\right.$ для $\left.\mathrm{Fe}\right), N_{\mathrm{SF}}-$ собственная концентрация атомов титана в его диоксиде $\left(N_{\mathrm{SF}}=3.2 \cdot 10^{22} \mathrm{~cm}^{-3}\right), r$ - доля реакционноспособных атомов титана в его диоксиде.

В качестве начальных условий при моделировании перераспределения компонентов для последующего вакуумного отжига принимались результаты моделирования концентрационных распределений, полученные в процессе магнетронного распыления железа на $\mathrm{TiO}_{2}$.

Система уравнений (2)-(6) с концентрационно зависимым эффективным коэффициентом взаимодиффузии (7) решалась численно методом факторизации с использованием консервативных неявных разностных схем [25].

Параметрами модели являлись: индивидуальные коэффициенты диффузии металлов, константа скорости реакции замещения титана железом на границах зерен (1) и доля реакционноспособных атомов титана в пленке $\mathrm{TiO}_{2}$. Численным анализом экспериментальных концентрационных распределений компонентов в рамках модели определены значения индивидуальных коэффициентов диффузии железа $D_{\mathrm{A}}=3.0 \cdot 10^{-13} \mathrm{~cm}^{2} / \mathrm{c}$ и титана $D_{\mathrm{C}}=2.0 \cdot 10^{-16} \mathrm{~cm}^{2} / \mathrm{c}$ для магнетронного распыления и для отжига при $1073 \mathrm{~K}$ : 
$D_{\mathrm{A}}=8.0 \cdot 10^{-13} \mathrm{~cm}^{2} / \mathrm{c}, D_{\mathrm{C}}=3.0 \cdot 10^{-15} \mathrm{~cm}^{2} / \mathrm{c}$, при неизменных $k_{1}=6.0 \cdot 10^{-23} \mathrm{~cm}^{3} / \mathrm{c}$ и $r=0.008$. При этих значениях параметров достигнуто хорошее соответствие экспериментальных распределений (символы $1-4$ ) расчетным для полных концентраций железа $\left(C_{\mathrm{A}}+C_{\mathrm{D}}\right)$ (рис. 2 , кривые $\left.1^{\prime}, 3^{\prime}\right)$ и титана $\left(C_{\mathrm{B}}+C_{\mathrm{C}}+C_{\mathrm{F}}\right)$ (рис. 2 , кривые $2^{\prime}, 4^{\prime}$ ).

Модель объясняет появление свободного титана на межфазной границе со стороны железа (рис. 2, кривые $2^{\prime \prime}, 4^{\prime \prime}$ ) как результат высвобождения его в ходе реакции (1) и диффузии в пленку железа. Перегиб на концентрационных распределениях полного железа (рис. 2, кривые $1^{\prime}, 3^{\prime}$ ) на МФГ со стороны $\mathrm{TiO}_{2}$ обусловлен концентрационной зависимостью коэффициента взаимодиффузии и захватом свободного железа (рис. 2, кривые $1^{\prime \prime}, 3^{\prime \prime}$ ) на ловушечные центры. Однородный участок распределения железа в оксиде титана отражает постоянство концентрации ловушечных центров по глубине пленки.

Глубокое проникновение $\mathrm{Fe}$ в пленку $\mathrm{TiO}_{2}$ оказывается возможным из-за малой скорости реакции замещения железом титана на поверхности зерен рутила. Действительно, оценка радиуса взаимодействия $R$ из соотноше-

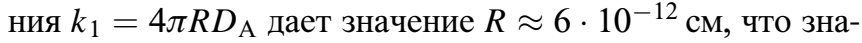
чительно меньше типичных значений $(0.1-1) \cdot 10^{-8} \mathrm{~cm}$ для лимитируемых диффузией твердотельных реакций. Малая скорость реакции (1) обусловлена, по-видимому, высокой прочностью связи Тi-O.

\section{5. Заключение}

Комплексным исследованием взаимодиффузии и фазообразования в пленочной системе $\mathrm{Fe}-\mathrm{TiO}_{2}$ при магнетронном распылении металла на оксид установлено образование оксида железа $\mathrm{Fe}_{3} \mathrm{O}_{4}$. В процессе изотермического отжига в интервале температур 673-1073 K формируется гетерофазная пленка, содержащая оксиды железа и титана, а также сложные оксиды на их основе: ильменит $\mathrm{FeTiO}_{3}$ ромбоэдрической структуры и ульвошпинель $\mathrm{Fe}_{2} \mathrm{TiO}_{4}$ кубической модификации. При всех температурах отжига сохраняется оксид титана в структуре рутила и металлическое железо.

Предложен механизм формирования сложных оксидов, основанный на реакционной диффузии переходного металла $\mathrm{Fe}$ по межзеренным границам оксида титана. Образование сложных оксидов происходит по всей толщине пленки $\mathrm{TiO}_{2}$ на границах зерен и не сопровождается изменением мольного объема системы. Разработана количественная модель, развивающая теорию [21] на случай реакционной взаимодиффузии в двухслойных пленочных поликристаллических системах металл-оксид с ограниченной растворимостью компонентов. Численным анализом экспериментальных концентрационных распределений компонентов в рамках разработанной модели определены значения индивидуальных коэффициентов диффузии железа и титана в системе $\mathrm{Fe}-\mathrm{TiO}_{2}$. Модель позволяет хорошо описать основные закономерности процесса: появление титана в пленке железа и глубокое проникновение $\mathrm{Fe}$ в пленку оксида титана, а также объяснить образование сложных оксидов не путем послойного роста на границе раздела металл-оксид, а по всей толщине пленки $\mathrm{TiO}_{2}$.

\section{Список литературы}

[1] J.O. Carneiro, V. Teixeira, A. Portinha, A. Magalhaes, P. Countinho, C.J. Tavares. Mater. Sci. Eng. B, 138 (2), 144 (2007).

[2] Meng Ni, Michael K.H. Leung, Dennis Y.C. Leung. K. Sumathy. Renew. Sustainable Energy Rev., 11 (3), 401 (2007).

[3] K. Zakrzewska, M. Radeska, M. Rekas. Thin Sol. Films, 310, 161 (1997).

[4] N.I. Al-Salim, S.A. Bagshaw, A. Bittar, T. Kemmitt, A.J. McQuillan, A.M. Mills, M.J. Ryan. J. Mater. Chem., 10, 2358 (2000).

[5] S. Sooda, A. Umarb, S.K. Mehtaa, S.K. Kansald. J. Colloid Interface Sci., 450, 213 (2015).

[6] P. Jianga, W. Xianga, J. Kuanga, W. Liu, W. Cao. Solid State Sci., 46, 27 (2015).

[7] Hsin-yu Lin, Cheng-yao Shih. J. Mol. Catal. A: Chem., 411, 128, (2016).

[8] F.B. Lia, X.Z. Lia, M.F. Houb. Appl. Catal. B, 48 (3), 185 (2004).

[9] H. Eskandarloo, A. Badiei, M.A. Behnajady, G.M. Ziarani. Ultrason. Sonochem., 26, 281 (2015).

[10] I. Ganesh, P.P. Kumar, A.K. Gupta, P.S.C. Sekhar, K. Radha, G. Padmanabham, G. Sundararajan. Proc. Appl. Ceramics, 6, 21 (2012).

[11] R.A. Briggs, A. Sacco. Metall. Trans. A, 24 (6), 1257 (1993).

[12] M. Crişana, N. Drăgana, D. Crişana, A. Ianculescub, I. Niţoic, P. Oancead, L. Todana, C. Stana, N. Stănicăa. Ceram. Int., 42 (2), 3088 (2016).

[13] Huey-Jiuan Lina, Tien-Syh Yanga, Chi-Shiung Hsia, MooChin Wangb, Kuen-Chan Leeb. Ceram. Int., 40 (7), 10633 (2014).

[14] A. Sobczyk-Guzendaa, S. Owczareka, H. Szymanowskia, L. Voleskyb, B. Walkowiaka, S. Miszczaka, M. GazickiLipmana. Ceram. Int., 41 (6), 7496 (2015).

[15] R. Dholam, N. Patel, M. Adami, A. Miotello. Int. J. Hydrogen Energy, 34 (13), 5337 (2009).

[16] C. Silvaa, A.R.G. Costaa, R.C. da Silvac, L.C. Alvesd, L.P. Ferreiraa, M.D. Carvalhof, N. Francoc, M. Godinhoa, M.M. Cruza. J. Magn. Magn. Mater., 364, 106 (2014).

[17] В.С. Русаков, И.А. Сухоруков, А.М. Жанкадамова, К.К. Кадыржанов. Вестн. МГУ. Сер. 3, Физика, астрономия, 3, 25 (2012).

[18] JCPDS - International Centre for Diffraction Data, 2012.

[19] D. Cordischi, N. Burriesci, F. D’Alba, M. Petrera, G. Polizzoti, M. Schiavello. J. Solid State Chem., 56, 182 (1985).

[20] A.D. Smigelskas, E.O. Kirkendall. Trans. AIME, 171, 130 (1947).

[21] L.S. Darken. Trans. AMIE, 175, 184 (1948).

[22] К.П. Гуров, Б.А. Карташкин, Ю.Э. Угасте. Взаимная дифбузия в многофазных металлических системах (М., Наука, 1981). 
[23] N.S. Kulkarni, R.J. Bruce Warmack, B. Radhakrishnan, J.L. Hunter, Y. Sohn, K.R. Coffey, G.E. Murch, I.V. Belova. J. Phase Equilib. Diffusion, 35 (6), 762 (2014).

[24] О.В. Александров, В.В. Козловский. ФТП, 43,(7), 917 (2009).

[25] А.А. Самарский. Теория разностных схем (М., Наука, 1977).

Редактор А.Н. Смирнов

Interdiffusion and phase formation in the $\mathrm{Fe}-\mathrm{TiO}_{2}$ thin films system

N.N. Afonin ${ }^{1}$, V.A. Logacheva ${ }^{2}$

${ }^{1}$ Voronezh State Pedagogical University, 394043 Voronezh, Russia

${ }^{2}$ Voronezh State University, 394018 Voronezh, Russia

Abstract The methods of $X$-ray diffraction analysis, secondary ion mass spectrometry, atomic force microscopy and mathematical modeling was used to study the interaction during isothermal vacuum annealing of the iron films prepared by magnetron sputtered method on the titanium oxide films. The mechanism of the formation of complex oxides at the grain boundaries based on the reaction diffusion of the $\mathrm{Fe}$ atoms into titanium oxide was proposed. A quantitative model of the reaction interdiffusion in twolayer systems of the polycrystalline metal-oxide film with limited solubility components has been developed. Numerical analysis of experimental concentration distributions of iron and titanium, the values of their individual diffusion coefficients in the $\mathrm{Fe}-\mathrm{TiO}_{2}$ films system during isothermal vacuum annealing at $1073 \mathrm{~K}$ was obtained: for Fe $8.0 \cdot 10^{-13} \mathrm{~cm}^{2} / \mathrm{s}$ and Ti $3.0 \cdot 10^{-15} \mathrm{~cm}^{2} / \mathrm{s}$. 